\title{
Normal growth in cystic fibrosis associated with a specialised centre
} Clare E Collins, Lesley MacDonald-Wicks, Selina Rowe, Edward V O’Loughlin,
Richard L Henry
Discipline of Nutrition and Dietetics,

University of

Newcastle, Callaghan

2308 NSW, Australia

C E Collins

L MacDonald-Wicks

S Rowe

Department of Gastroenterology, New

Children's Hospital, Westmead, Sydney 2145 NSW, Australia

E V O'Loughlin

School of Paediatrics, University of New South Wales,

Randwick, Sydney 2031

NSW, Australia

R L Henry

Correspondence to: Dr C E Collins, Department of Nutrition and Dietetics, John Hunter Children's Hospital, Locked Bag 1, Hunter Region Mail Centre, NSW, 2310, Australia. email: ccollins@ mail.newcastle.edu.au

Accepted 20 May 1999

\begin{abstract}
Objective-To assess the impact of lifetime continuous care within the John Hunter Hospital cystic fibrosis (CF) clinics on growth and lung function.

Design-A cross sectional survey of variables affecting nutritional status in CF was undertaken for 1993 and 1997. Data were retrieved from medical records and grouped into 5 year age bands.

Main outcome measures-Change in height $\mathrm{z}$-score, weight centile, and forced expiratory volume in one second $\left(\mathrm{FEV}_{1}\right)$ between patient cohorts receiving specialised care for different lengths of time.

Results-Improved mean height z-score $\left(\begin{array}{lll}-0.880 & v & -0.047)\end{array}\right)$ and weight centile $(28.3 \% v 48.1 \%)$ for the $10-15$ year age group in 1997, who had received continuous lifetime care within the clinic, compared with the same age group in 1993, for whom continuous medical care started at an older age. There was no corresponding improvement in $\mathrm{FEV}_{1}$, as an indicator of lung function, in this group $(81.6 \%$ predicted $v 89.5 \%$ predicted).

Conclusions-This study suggests that lifetime continuous care within a specialised CF centre is associated with improved growth but not improved lung function.
\end{abstract}

(Arch Dis Child 1999;81:241-246)

Keywords: cystic fibrosis; nutrition; height; weight; pulmonary function

In cystic fibrosis $(\mathrm{CF})$ an important correlation has been found between dietary intake, nutritional status, lung function, and survival. ${ }^{1}$ Relative underweight has been identified as prognostic of both severity of pulmonary disease and survival, ${ }^{2-4}$ with lung function shown to be correlated positively with percentage body fat ${ }^{5}$ and weight for height. ${ }^{6}{ }^{7}$ After the 1 st few years of life, weight and weight for height are more closely related to lung function than to pancreatic status. ${ }^{8}$

Growth and nutritional problems are common in CF. In the $\mathrm{UK}^{9}$ and $\mathrm{USA}^{10}{ }^{10}$ regular attendance at a specialised CF centre has been shown to improve nutritional and clinical status, as well as life expectancy. Mahadeva et al have shown improved growth and lung function in adults with CF, associated with lifetime provision of medical care within a specialised CF centre, compared with both provision of non-specialist CF care or the provision of specialist CF care from adulthood only. ${ }^{11}$
Most patients with CF born since the early 1980s in the Hunter Region of New South Wales, Australia were identified by newborn screening; from 1982, the dietary recommendation was a high fat intake. In 1984 a specialised, multidisciplinary CF clinic was established in the Hunter Region by RLH. A specialist dietitian (CEC) was appointed from 1986 with the goal of preventing growth failure in $\mathrm{CF}$, once a diagnosis had been made. In 1992 a cross sectional review of the growth of CF patients revealed poor growth in both sexes over the age of 10 years (figs 1 and 2). For example, there were no male patients over the age of eight years whose height was $>50$ th centile. However, it was unclear whether this phenomenon, in line with that reported in other CF clinics, ${ }^{12}$ was irrevocable because it represented the natural history of $\mathrm{CF}$, or whether the improved growth of the younger subjects receiving lifetime care would be sustained. Therefore, the aims of our study were: (1) to compare the growth data of our CF clinic with those of the normal population; and (2) to compare changes in growth and clinical status (1993-7) of the patient cohort receiving lifetime care from our clinics compared with the cohort who did not, based on year of diagnosis.

\section{Methods}

We reviewed the growth and clinical status of all patients attending the John Hunter Hospital cystic fibrosis clinic between 1993 and 1997. Clinical data were retrieved from the medical notes referring to the outpatient visit closest in date to February 1993 and February 1997 for all patients attending the paediatric and adult clinics ( $\mathrm{n}=76$ in 1993; $\mathrm{n}=95$ in 1997). Growth data were plotted directly on to centile charts (figs 1 and 2). The solid vertical line represents the maximum age of those born since the clinic was established in 1984 who, by implication, have had the opportunity to be managed there for all of their lives.

Clinical data for the patients who transferred into the clinic were excluded from analysis. The last data recorded in the medical record before death were entered in 1997 for five of the six patients who died between 1993 and 1997. Exit data from the three patients who transferred out were also included from their last outpatient clinic visit.

\section{CLINICAL DATA MEASUREMENTS}

The methods of Cameron were used for all the anthropometric measures. ${ }^{13}$ Heights were measured with a stadiometer (Holtain, Crymych, Dyfed, UK). Weights were recorded to 
the nearest $0.01 \mathrm{~g}$ on GEC/Avery digital scales (model number $824 / 890$ ), with subjects wearing only minimal underwear. Height was expressed as a Z-score and weight as per cent ideal weight for height. Both were calculated using a Kabi Pharmacia (Stockholm, Sweden) growth calculator. Clinical status was measured as part of routine clinical care by the Shwachman score (SS). This score is derived from an appraisal of the four categories of general activities, physical examination, nutritional status, and $x$ ray findings. ${ }^{14}$ Each item is given a weighting of 25 points. Chest $x$ rays were scored in a blind manner by a respiratory paediatrician. Forced expiratory volume in one second $\left(\mathrm{FEV}_{1}\right)^{15}$ was expressed as the percentage predicted based on weight and height. Faecal fat excretion (FFE) was determined from the results of a three day stool sample collected in conjunction with a four day weighed food record. Faecal fat was estimated using the methods of Van der Kamer, ${ }^{16}$ and excretion was expressed as the per cent of the total dietary fat intake that was excreted ( $\% \mathrm{FFE})$. Information on genotype and biochemical data was extracted from patients' records or from the Hunter area pathology database.

\section{STATISTICAL ANALYSES}

Statistical analysis was performed using Minitab Release 12 for Windows (MINITAB Inc, State College, Pennsylvania, USA). All differences were considered significant at $\mathrm{p} \leqslant 0.05$. Variables are reported as mean (SD), unless otherwise stated. Statistical comparisons between two groups were performed using the Student's $t$ test for normally distributed variables and the Mann-Whitney nonparametric test for non-normal variables. ANOVA was used for comparisons of more than two groups. The data were grouped on the basis of 5 year age brackets. The differences between these groups in 1993 and 1997 were compared using a one sample Student's $t$ test for normal data and the Wilcoxon rank sum test for non-normal variables. The $\mathrm{z}$-scores for height were compared with the normal population using a z-test with $\sigma=1$.

Male height growth 1992-97
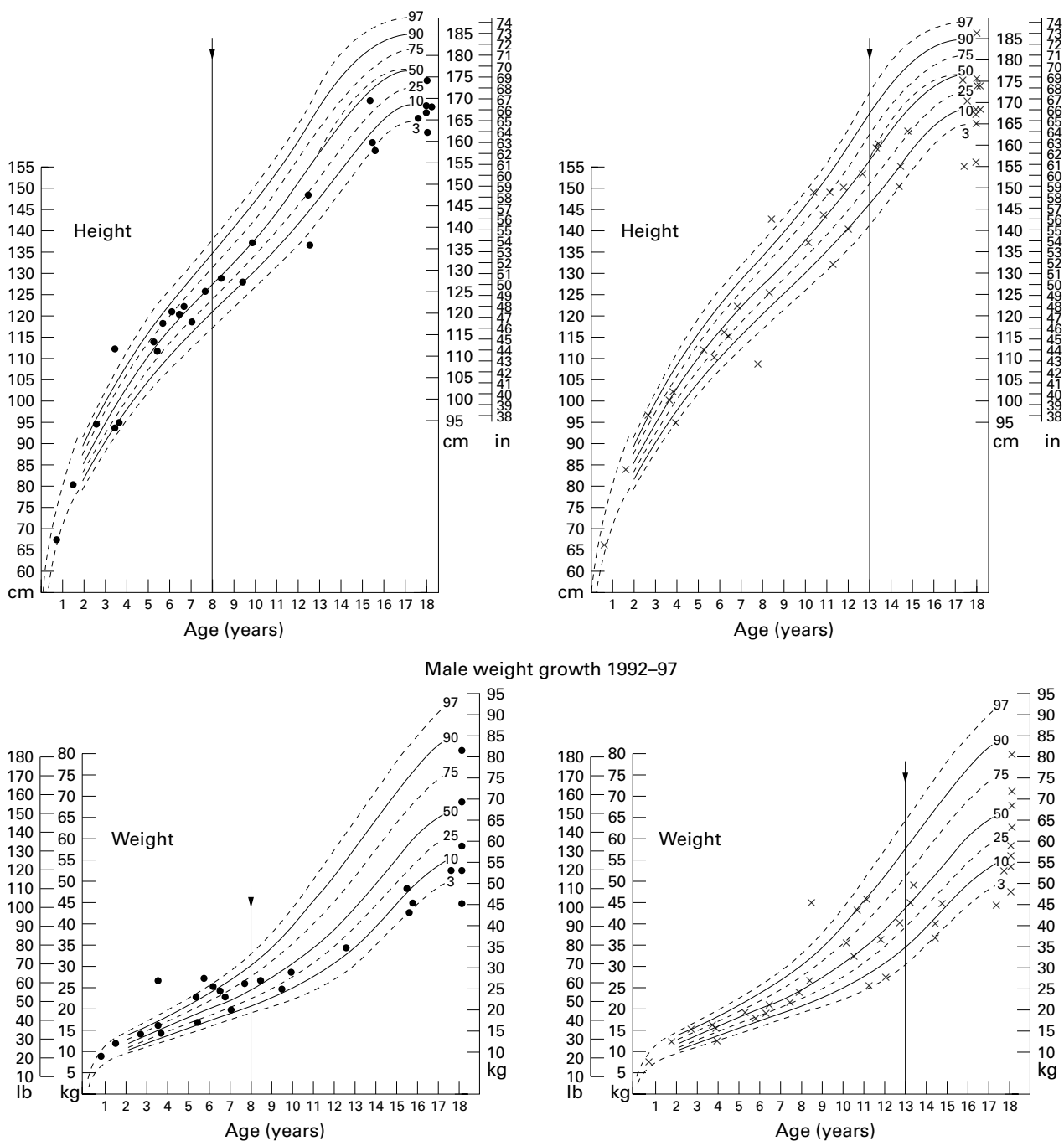

Figure 1 Improvements in male height and weight centiles 1992-7. The left panel displays the 1992 height and weight centiles, and the right the 1997 centiles, for the outpatient clinic visit closest to February in each year, for all patients attending the fohn Hunter Hospital cystic fibrosis (CF) clinic. The arrowed vertical line indicates the maximum age of patients receiving lifetime care within a Hunter area CF clinic. 
Female height growth 1992-97
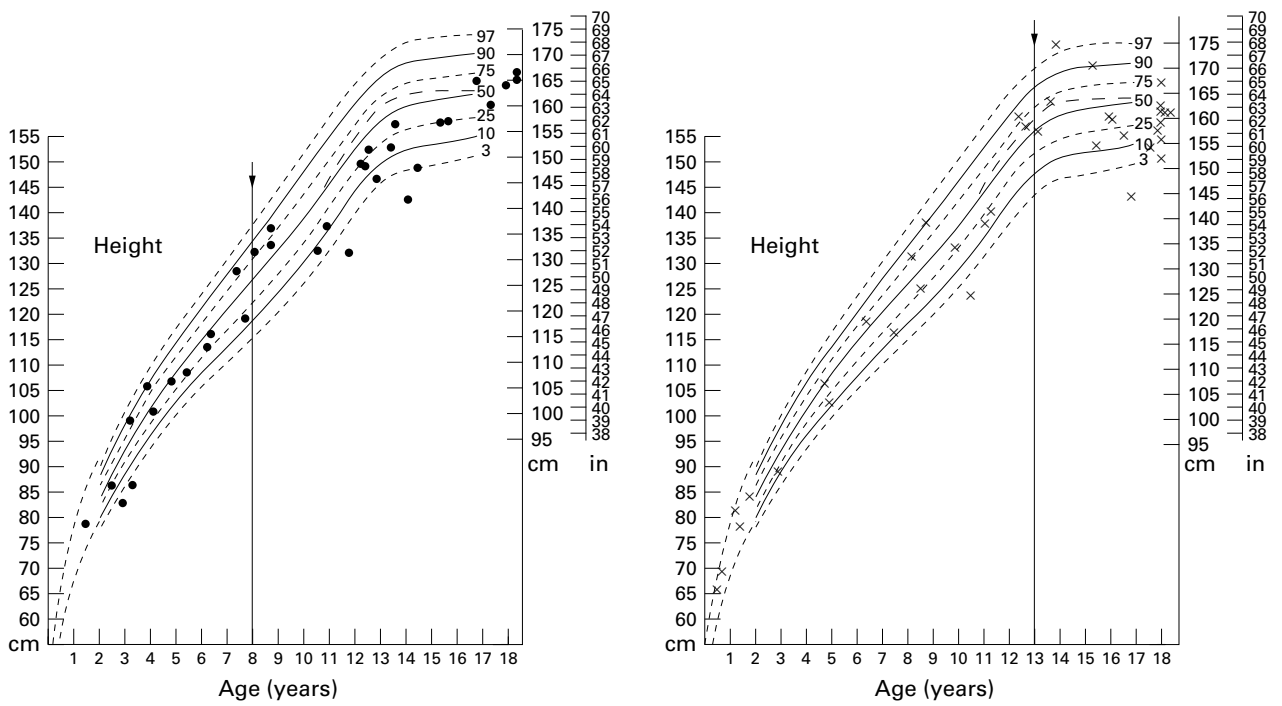

Female weight growth 1992-97
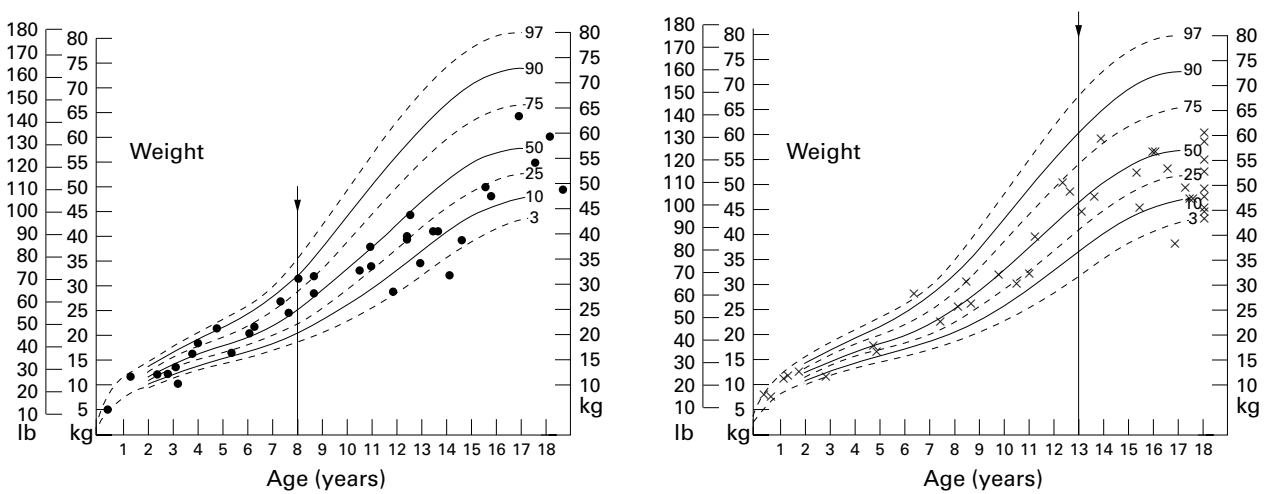

Figure 2 Improvements in female height and weight centiles 1992-7. The left panel displays the 1992 height and weight centiles, and the right the 1997 percentiles, for the outpatient clinic visit closest to February in each year, for all patients attending the fohn Hunter Hospital cystic fibrosis (CF) clinic. The arrowed vertical line indicates the maximum age of patients receiving lifetime care within a Hunter area CF clinic.

\section{Results}

DEMOGRAPHIC CHARACTERISTICS 1993-7

Table 1 gives the clinical characteristics of the patients in 1993 and 1997 and they indicate that, on average, patients had mild to moderate lung disease, were slightly height stunted, but had optimal weight for height, with good control of malabsorption. The genotype of our clinic population in 1993 has been reported previously, with an $80 \%$ prevalence of the $\Delta \mathrm{F} 508$ mutation. ${ }^{17}$ In 1997 , this prevalence was $81 \%$, with $62 \%$ homozygous for $\Delta \mathrm{F} 508$ and only one patient with two identified non$\Delta$ F508 mutations. Five patients were pancreatic sufficient, all heterozygous for $\Delta \mathrm{F} 508$. Fourteen per cent of the patients have insulin dependent cystic fibrosis related diabetes, (four male and eight female patients), which is a high prevalence compared with the commonly reported 3-12\%. ${ }^{18-20}$ By 1997, 11 patients had gastrostomies (mean age, 16.5; SD, 5.0 years), an increase from 1993 (mean age, 13.8; SD, 4.8 years)

Six patients died between 1993 and 1997 (two boys/men; four girls/women), nine were born, three transferred out, and 10 transferred in (six adults, all men; four children, three boys). Those transferring into the clinic were predominantly growth retarded men with moderate lung function and clinical status; we excluded them from our analysis.

GROWTH VARIABLES

Figure 1 illustrates the improvement in male heights and weights in the clinic 1992-7 and fig 2 illustrates the improvements in female heights and weights for the same period. Heights and weights were plotted on centile charts derived from the National Centre for Health Statistics. ${ }^{21}$ A comparison of these charts suggested improved growth in the cohort receiving lifetime care from our clinic.

In 1997, the mean z-score for height for the total CF population was significantly different from the normal population mean z-score of zero $(95 \%$ confidence interval (CI), -0.71 to $-0.28 ; \mathrm{p}<0.0001)$. However, when this was examined within 5 year age groups, the $\mathrm{z}$-score for height in the three groups up to the group $\leqslant 15$ years was not significantly lower than the normal population (table 2). For the two groups $>15$ years, $z$-score for height was significantly less than the normal population mean (table 2). When we made the same com- 
Table 1 Comparison of group mean and individual paired clinical data of patients attending the fohn Hunter Hospital cystic fibrosis clinic in 1993 and 1997

\begin{tabular}{|c|c|c|c|c|c|c|c|c|}
\hline \multirow[b]{2}{*}{ Clinical characteristics } & \multicolumn{3}{|c|}{1993} & \multicolumn{3}{|c|}{1997} & \multirow{2}{*}{$\begin{array}{l}\text { Group mean } \\
\text { p value }\end{array}$} & \multirow{2}{*}{$\begin{array}{l}\text { Paired data } \\
\text { p value }\end{array}$} \\
\hline & $n$ & Mean (SD) & Range & $n$ & Mean (SD) & Range & & \\
\hline Age (years) & 76 & $11.4(7.1)$ & 0.2 to 33.8 & 84 & $13.5(7.8)$ & 0.4 to 37.8 & 0.068 & NA \\
\hline Height z-score & 76 & $-0.50(1.1)$ & -3.2 to 2.0 & 84 & $-0.49(1.2)$ & -3.5 to 2.5 & 0.98 & 0.48 \\
\hline Height centile ${ }^{\star}$ & 76 & 28 & 1 to 98 & 84 & 32 & 0.9 to 100 & $0.81 \dagger$ & $0.76 \ddagger$ \\
\hline Weight centile ${ }^{\star}$ & 76 & 39.5 & 1 to 100 & 84 & 45 & 0.1 to 98 & $0.16 \dagger$ & $<0.001 \ddagger$ \\
\hline Ideal weight for height (\%) & 76 & $103.9(12.2)$ & 72 to 135 & 84 & $104.5(12.6)$ & 77 to 137 & 0.78 & 0.71 \\
\hline $\mathrm{FEV}_{1}(\%$ predicted $)$ & 56 & $85.7(23.5)$ & 16 to 128 & 67 & $77.6(25.2)$ & 18 to 144 & 0.068 & $<0.001$ \\
\hline$\%$ FFE & & ND & & 19 & $11.3(10.8)$ & $0.8-31$ & & ND \\
\hline
\end{tabular}

^Medians reported for non-parametric variables (height and weight centile); †Mann-Whitney test; $¥ W$ ilcoxon signed rank test on the paired difference, 1997 and 1993. $\mathrm{FEV}_{1}$ (\%predicted), forced expiratory volume in one second as a percentage of that predicted based on age, weight, and height; \% FFE, percentage of daily dietary fat intake excreted (good control of malabsorption in cystic fibrosis is < 15\% FFE); ND, no data; NA, not applicable.

Table 2 Comparison of mean height z-scores of the Fohn Hunter Hospital cystic fibrosis clinic population with the normal population (mean z-score, zero), within five year age groupings in 1993 and 1997

\begin{tabular}{lllll}
\hline Age group (years) & $n$ & $\begin{array}{l}\text { Height } z \text {-score } \\
(\text { mean })\end{array}$ & 95\% VI & \\
\hline $\begin{array}{l}\text { Height z-score } 1997 \\
\quad \text { to } \leqslant 5\end{array}$ & 14 & -0.00 & -0.52 to 0.52 & 1.0 \\
$\quad>5$ to $\leqslant 10$ & 14 & -0.41 & -0.93 to 0.12 & 0.13 \\
$>10$ to $\leqslant 15$ & 19 & -0.05 & -0.50 to 0.40 & 0.84 \\
$>15$ to $\leqslant 20$ & 19 & -0.98 & -1.43 to -0.54 & $<0.001$ \\
$>20$ & 18 & -0.89 & -1.35 to -0.43 & $<0.001$ \\
Height z-score 1993 & & & -0.78 to 0.14 & 0.17 \\
$\quad$ to $\leqslant 5$ & 18 & -0.32 & -0.19 to 0.76 & 0.24 \\
$>5$ to $\leqslant 10$ & 17 & 0.28 & -1.32 to -0.44 & $<0.001$ \\
$>10$ to $\leqslant 15$ & 20 & -0.88 & -1.49 to -0.36 & $<0.001$ \\
$>15$ to $\leqslant 20$ & 12 & -0.92 & -1.74 to -0.36 & 0.003 \\
$>20$ & 8 & -1.05 & &
\end{tabular}

Assumed $\sigma=1$.

parison in 1993, a normal z-score for height was seen only up to $\leqslant 10$ years (table 2 ). This indicates an important improvement in the growth variables of the $10-15$ year age group from 1993 to 1997 in the cohort receiving lifetime care from our clinic.

The mean height $\mathrm{z}$-scores within 5 year age groups were further compared from 1993 to 1997. There was a significant higher mean value in 1997 compared with 1993 in the $10-15$ year group (95\% CI, 0.20 to 1.31 ; $\mathrm{p}=0.044$ ) (fig 3). This was also reflected by a greater height centile in this group (95\% CI, 2.0 to $41.0 ; \mathrm{p}=0.035$ ).

The corresponding mean weight centile for the $10-15$ year age group was significantly greater in 1997 compared with 1993 (95\% CI, 1.0 to $30.3 ; p=0.037$ ) (fig 3 ). An examination by age group showed that in 1993 the mean weight centile for the 5-10 year group was significantly greater than the 50th centile $(p=0.03)$. In 1997, this extended up to the 10-15 year group, such that the group mean weight centile up to the 10-15 year group was not different from the 50th centile $(\mathrm{p}>0.05)$. Again, this indicated continuing improved growth in the cohort who had received lifetime specialised CF care compared with the cohort who had not.

PULMONARY FUNCTION

We compared pulmonary function data for 1993 and 1997 within the 5 year age groups to ascertain if there had been any changes in association with the improvement in growth in the 10 to 15 year age group. There was a small but not significantly greater $\mathrm{FEV}_{1} \%$ predicted for this age group in 1997 compared with 1993 $(95 \% \mathrm{CI},-17.4$ to $7.3 ; \mathrm{p}=0.4)$. In the $15-20$
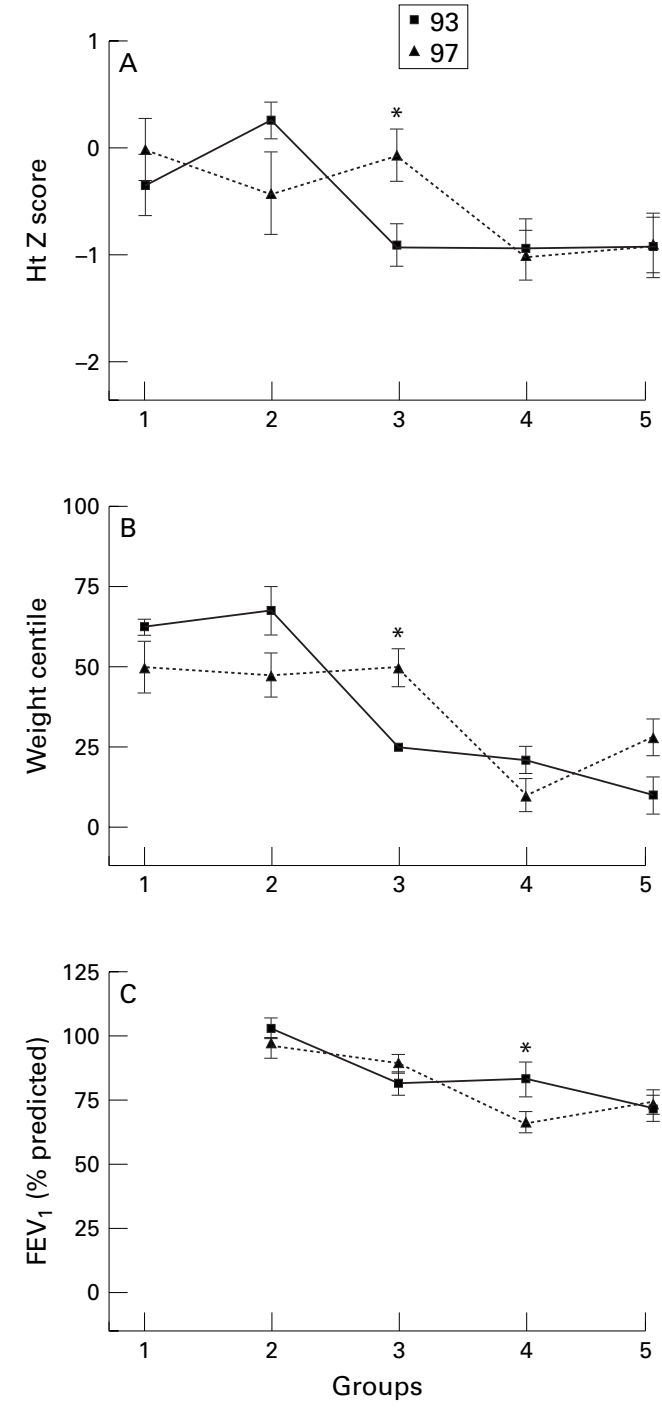

Figure 3 Comparison of mean height z-scores, mean weight centile, and mean $F E V_{1} \%$ predicted (forced expiratory volume in one second as a percentage of that predicted based on age, weight, and height), within 5 yea age groups, 1993-7. *Significantly greater mean height $z$-score and weight centile in $1997(p=0.04)$ and lower mean $\mathrm{FEV} V_{1} \%$ predicted in the 15-20 year old age group (excluding data on patients who died) $(p=0.04)$. Comparison of lung function excludes patients who died between 1993 and 1997. Values are mean (SEM).

year olds there was a significantly lower mean $\mathrm{FEV}_{1} \%$ predicted (95\% CI, 4.4 to 38.9; $\mathrm{p}=0.016)$ in 1997 compared with 1993. The change in $\mathrm{FEV}_{1}$ for this age group was confounded by the inclusion of data recorded immediately before death in six patients in the 
1997 data. However, fig 3 highlights that when these data were excluded the lower mean $\mathrm{FEV}_{1}$ $\%$ predicted in the $199715-20$ year olds remains significant $(95 \% \mathrm{CI}, 1.2$ to 32.9 ; $\mathrm{p}=0.036)$.

\section{OTHER}

The 1992 growth data presented in figs 1 and 2 prompted a comparison of clinical variables for the two years 1993 and 1997. Table 1 illustrates the mean (SD) or median and range in the cross sectional clinical characteristics of all the patients attending the CF clinics in 1993 and 1997. There were no significant changes in the median height centile $(\mathrm{p}=0.8)$ or median weight centile $(p=0.16)$ over this time.

An examination of individual paired growth data over the 1993-1997 period found a highly significant decrease in weight centile $(n=75$; $\mathrm{p}<0.001 ; 95 \% \mathrm{CI}, 5.0$ to 13.5$)$ and lung function $(\mathrm{n}=53 ; \mathrm{p}<0.001 ; 95 \% \mathrm{CI}, 10.5$ to 19.1).

We analysed the 1997 and 1993 clinical characteristics by sex and found no significant differences in age or growth characteristics. However, there was a significantly greater four year decline in $\mathrm{FEV}_{1}$ in the girls/women of $19.4 \%$ predicted $v 9.2 \%$ predicted in the boys/ men (95\% CI, 2.1 to $18.4 ; \mathrm{p}=0.015)$. When the 1997 data from the patients who died were excluded, this difference remained significant (95\% CI, 1.3 to $19.0 ; p=0.025)$. Although the decline in $\mathrm{FEV}_{1}$ within each age group was consistently greater in the girls/women, it did not reach significance.

\section{Discussion}

Our study highlights that aggressive nutrition promotion from diagnosis, within a specialist $\mathrm{CF}$ clinic, normalises growth. However, this improvement in growth variables did not result in improved pulmonary function. This suggests that improved prognosis in patients with $\mathrm{CF}$ is the result of the secondary benefits associated with optimal medical care and nutritional support.

By definition, when comparing the growth of our patients with the National Centre for Health Statistics international reference standards, we expected the mean height $z$-score to be zero, if the population was growing normally. In addition, $50 \%$ of patients should have a weight and height lying below the 50th centile. The data presented here indicate that on average, the growth variables of our population are still not ideal. However, the mean z-score for height, reported by 5 year age groups, highlight that it is only the older patients who have inferior height gain. The mean height $\mathrm{z}$-scores in 1997 for patients < 15 years of age are normal. In 1993, only the patients $<10$ years had normal z-scores for height, but in 1997 this increased to all groups $<15$ years. The significant improvements in both height and weight between 1993 and 1997 in the 10-15 year age group reinforce our view that the younger cohort of patients, who have received lifetime care from the specialised CF clinic, maintained better growth variables up to the age of 15 years than did the previous cohort, whose access to specialised CF care began at an older age.

Historically, growth failure was a recognised and accepted feature of $\mathrm{CF}^{22}$ with relative underweight being prognostic of both the severity of pulmonary disease and survival. ${ }^{2-4}$ Growth retardation in CF is now thought to be largely preventable, ${ }^{12}$ with controls and children with $\mathrm{CF}$ having similar growth potentials. ${ }^{23}$ Puberty has been recognised as a time when deterioration in clinical status can accelerate, particularly in girls. ${ }^{24}$ Because puberty is commonly delayed in $\mathrm{CF}^{25}{ }^{26}$ follow up over the next five years will reveal if this improvement in growth is sustained. Follow up will also help to assess the impact of lifetime care in a specialised CF clinic on nutritional status, progression of lung disease beyond the second decade and, eventually, life expectancy.

Survival is worse for patients underweight for height, ${ }^{2}$ and this effect is greater in patients with poor lung function as opposed to poor absorption status. ${ }^{38}$ Neonatal screening programmes suggest that an energy and nutritional deficit exists before the onset of symptoms. ${ }^{27-29}$ However, we have shown that the deficit can be overcome and normal growth achieved. $^{28}{ }^{30}$ The fact that height growth has not been normalised in the older age groups suggests an irreversible effect of less frequent clinical care in the early years of life and most likely a later diagnosis. This supports the findings of Mahadeva et $a l,{ }^{11}$ who compared the growth and pulmonary function of three groups of adults with CF, namely: (1) those receiving continuous care from paediatric and then adult CF centres; (2) those receiving nonspecialised paediatric care, followed by specialist adult care; and (3) those who had received no specialised care. Body mass index correlated positively with increasing amounts of care $(\mathrm{p}<0.001)$, and improved nutritional status was associated with a higher $\mathrm{FEV}_{1}$ and lower chest $x$ ray scores $(\mathrm{p}<0.001) .{ }^{11}$

Despite a bias towards improved mean growth characteristics in our 1993 data, because no deaths were included for this year, the 1997 growth characteristics of the 10-15 year old age group still showed improvements in height z-score, and height and weight centiles. However, when the data from patients who died between 1993 and 1997 were excluded there was still no improvement in $\mathrm{FEV}_{1} \%$ predicted in the 10-15 year olds, with a significant decline in lung function in the 15-20 year olds. These data from the oldest patients could have a positive bias if there was an excess of early deaths before the establishment of the clinic in 1984. However, our findings highlight that even though deteriorating growth and lung function go hand in hand, prevention of deterioration in growth does not prevent deterioration in lung function.

There was no sex difference in lung function in the 5-10 year group in either 1993 or 1997. However, the greater four year decline in $\mathrm{FEV}_{1}$ $\%$ predicted in the girls suggests that more rapid deterioration in lung function may begin before puberty, as has been suggested 
recently. ${ }^{24}$ This supports the view that the sex related decline in lung function is not nutrition related.

Vaisman et al noted a positive correlation between lung function and per cent body fat, ${ }^{5}$ whereas both Bogle and colleagues ${ }^{6}$ and Zemel and colleagues ${ }^{7}$ noted a positive correlation between weight for height and lung function. It has been reported that after the $1 \mathrm{st}$ few years of life, weight and weight for height are more closely related to lung function than to pancreatic status. ${ }^{8}$ Our growth data support this. We noted very strong correlations between weight centile and lung function in both 1993 and 1997. Weight centile was the most important predictor of $\mathrm{FEV}_{1}$ in a regression analysis, and explained almost a third of the variation in pulmonary function. Although this has been shown before, ${ }^{6-8}$ it is worth noting that this relation still holds in a group who are relatively well nourished and have mild lung disease. This suggests that even moderate deterioration in lung function is inevitably associated with weight loss.

In conclusion, our study shows how the problem of height stunting and poor weight gain in pre-adolescent patients with $\mathrm{CF}$ can be ameliorated when prevention of growth failure from diagnosis is a high priority of the $\mathrm{CF}$ team. If one of the aims of the care of patients with $\mathrm{CF}$ is to normalise growth, then a dedicated $\mathrm{CF}$ dietitian is a fundamentally important member of the team. However, our data also demonstrate that we achieved no impact on deterioration in pulmonary function, and the effect on prognosis remains to be determined.

The authors acknowledge the dedication of the CF team to ongoing care and support of young people with $\mathrm{CF}$ and their families, especially Dr DM Cooper, Sr J Cordwell, and R Hankin.

1 Gaskin, KJ. The impact of nutrition in cystic fibrosis: a review. F Pediatr Gastroenterol Nutr 1988;7(suppl 1):S1217

2 Sproul A, Huang N. Growth patterns in children with cystic fibrosis. F Pediatr 1964;65:664-76.

3 Kraemer R, Rudeberg A, Hadorn B, Rossi E. Relative underweight in cystic fibrosis and its prognostic value. Acto Paediatr Scand 1978;67:33-7.

4 Gaskin K, Gurwitz D, Durie P, et al. Improved respiratory prognosis in patients with normal fat absorption. $\mathcal{F}$ Pediatr 1982;100:857-62.

5 Vaisman N, Pencharz PB, Corey M, Canny GJ, Hahn E. Energy expenditure of patients with cystic fibrosis. F Pediatr 1987;111:496-500.

6 Bogle ML, Alford BA, Warren R, King SE. Estimating calorie needs of prepubescent children with cystic fibrosis. Top Clin Nutr 1990;5:47-58.
7 Zemel BS, Kawchak DA, Cnaan A, Zhao H, Scanlin TF, Stallings VA. Prospective evaluation of resting energy expenditure, nutritional status, pulmonary function, and genotype in children with cystic fibrosis. Pediatr Res 1996;40:578-86.

8 Byard PJ. Relationship between clinical parameters and linear growth in children with cystic fibrosis. American fournal of Human Biology 1989;1:719-25.

9 British Paediatric Working Party on Cystic Fibrosis. Cystic fibrosis in the United Kingdom 1977-85: an improving picture. BMF 1988;297:1599-602.

10 FitzSimmons SC. The changing epidemiology of cystic fibrosis. F Pediatr 1993;122:1-9.

11 Mahadeva R, Webb K, Westerbeek R, et al. Clinical outcome in relation to care in centres specialising in cystic fibrosis: cross sectional study. BMF 1998;316:1771-5.

12 Soutter VL, Kristidis P, Gruca MA, Gaskin KJ. Chronic undernutrition/growth retardation in cystic fibrosis. Clin Gastroenterol 1986;15:137-55.

13 Cameron N. Human growth, Vol. 2. New York: Plenum Press, 1978:35-90.

14 Shwachman H, Kulczycki LL. Long-term study of one hundred and five patients with cystic fibrosis: studies made over a 5 to 14 year period. Am F Dis Child 1958;96:6-15.

15 Pierce R, Johns DP. Spirometry. Melbourne: National Asthma Campaign Ltd, 1995.

16 Van der Kamer JH, Huinick H, Weyers HA. Rapid method for determination of fat in feces. F Biol Chem 1949;177: $347-55$.

17 Henry RL, Hettiarachchi LC, Colley P, Collins C, O'Loughlin EV, Cooper DM. Genotype of the cystic fibrosis population of the Hunter Region of New South Wales. $\mathcal{F}$ Paediatr Child Health 1996;32:416-18.

18 Consensus Committee. Consensus conference on CF-related diabetes mellitus, Vol. I, Section IV. Bethesda: Cystic Fibrosis Foundation, 1990:1-8.

19 Dodge JA, Morrison G. Diabetes mellitus in cystic fibrosis: a review. F Roy Soc Med 1992;85:25-8.

20 Pfeifer T. Diabetes in cystic fibrosis. Clin Pediatr (Phila) 1992;31:682-7.

21 United States Public Health Service. National Centre for Health Statistics growth charts, Rockville, MD: 1976. In: Measuring changing nutritional status. Geneva: World Health Organisation, 1983.

22 Durie PR, Pencharz, PB. Nutrition: nutritional deficiencies in cystic fibrosis. Br Med Bull 1992;48:823-47.

23 Sturgess JM. The heights of CF patients aged 2-9 years allowing for parental height and severity of pulmonary function episodes from birth. In: Perspectives in cystic fibrosis. The Imperial Press, 1980:262-5.

24 Rosenfeld M, Davis R, FitzSimmons S, Pepe M, Ramsey B. Gender gap in cystic fibrosis mortality. Am 7 Epidemiol 1997; 145:794-803.

25 Phelan PD, Landau LI, Olinsky A. Cystic fibrosis. Respiratory illness in children, 3rd ed. Oxford: Blackwell Scientific Publications, 1990:192-233.

26 Jojannesson M, Gottlieb C, Hjelte L. Delayed puberty in girls with cystic fibrosis despite good clinical status. Pediatrics 1997;99:29-34.

27 Greer R, Shepherd RW, Cleghorn GJ, Bowling FG, Holt T. Evaluation of growth and changes in body composition following neonatal diagnosis of cystic fibrosis. I Pediatr Gastroenterol Nutr 1991;13:52-8.

28 Mischler EH, Marcus MS, Sondel SA, et al. Nutritional assessment of infants with cystic fibrosis diagnosed through screening. Pediatr Pulmonol Suppl 1991;7:56-63.

29 Morrison JM, O'Rawe AM, McCraken KJ, Redmond A, Dodge JA. Energy intake and losses in cystic fibrosis. four nal of Human Nutrition and Dietetics 1994;7:39-46.

30 Shepherd RW, Thomas BJ, Bennett D, Cooksley WG, Ward LC. Changes in body composition and muscle protein degradation during nutritional supplementation in nutritionally growth-retarded children with cystic fibrosis. $\mathcal{F}$ Pediatr Gastroenterol Nutr 1983;2:439-46. 